\title{
Experimental study of channelization by seepage erosion
}

\author{
Adichai PORNPROMMIN* and Norihiro IZUMI** \\ ${ }^{*}$ D.Eng., Lecturer, Dept. Water Resources Eng., Kasetsart Univ. \\ (Jatujak, Bangkok, Thailand 10900) \\ ${ }^{* *}$ Ph.D., Professor, Dept. Civil Eng., Hokkaido Univ. \\ (Kita-ku, Sapporo, Hokkaido 060-8628)
}

\begin{abstract}
Seepage erosion has been hypothesized as one of the dominant factors of channelization in both sediment and rock. However, the actual erosion mechanism responsible for seepage erosion is not fully understood. Recently, the importance of seepage erosion in rock is widely discussed. As a reason, this study aims to fulfill a lack of the fundamental knowledge in the seepage erosion mechanism. A series of the experiments on seepage erosion in wide chamber is conducted with varying sediment layer thickness, chamber slope and discharge. Artificial plastic pellets are used as cohesionless sediment. Channelization is found to be strongly influenced by water discharge. Amphitheater head of channels are observed in every experiment. The effects of chamber slope and sediment layer thickness result in different characteristics of channelization.
\end{abstract}

Key Words : channelization, seepage erosion, experiment, cohesionless sediment

\section{Introduction}

Erosions by overland flow and seepage have been hypothesized as the dominant factors in the initiation and evolution of gullies and channels. Many studies on channelization due to erosion by overland flow have been carried out ${ }^{1), 2), 3), 4), 5)}$, whereas fewer studies have focused on seepage erosion. According to Dunne ${ }^{6)}$, seepage is defined as groundwater that emerges from rock or sediment, and seepage erosion is defined as the removal of mass from a seepage face. Howard and McLane ${ }^{7)}$ conducted a series of experiments in a narrow chamber (the two-dimensional experiments). At the upstream end of the chamber, the constant water depth was set, and, at the downstream end, the outflow was fixed at the level of the chamber base. The longitudinal profile of the sediment layer forms a trapezoidal shape in the chamber, where subsurface water flows from the upstream end through the sediment and emerges at the downstream scarp (the seepage face). They proposed three major process zones on the face, sapping zone, undermining zone and fluvial zone. The sapping zone is the zone of seepage outflow, the undermining zone is the combined dry and damp sand faces above the sapping zone, and the fluvial zone is the downstream of the sapping zone, where surface water flows on the chamber bed covered with several grain diameters thickness, and grains move individually as bed load. From their experiments, they concluded that the rate of seepage erosion in cohesionless sediment can be deter- mined by the capacity of fluvial transport to remove sediment eroded in the sapping zone.

Subsequently, the studies of channelization by seepage erosion in wide chambers (the three-dimensional experiments) were conducted. Howard ${ }^{8)}$ conducted the experiments in an aluminum tank 5 feet square and 2 feet high with cohesionless and slightly cohesive sands. He found that high flow rates cause more active channels with wider widths, and channels are narrower and deeper in the case of slightly cohesive sand. Kochel and Piper ${ }^{9)}$ conducted the experiments using fine and coarse sands in the flume with broader width of $2.5 \mathrm{~m}$. They investigated the responses of channels to the effects of structural and/or stratigraphic variations in the surface in order to mimic the evolution of channels on the Hawaii Islands. They found that the light-bulb shape of headcut in plan (or large head width) is caused by the accelerated discharge. Groundwater piracy, in which one channel through headward erosion intercepts and pirates the flow of an adjacent channel, was observed in most experiments. Similar experiments in a different operational procedure were conducted by Gomez and Mullen ${ }^{10)}$. The drainage area of $1.8 \mathrm{~m}$ width using fine sand was formed a V-shaped cross section to encourage the development of a trunk stream at the center. While a constant head tank located upslope of sediment layer was used for groundwater recharge in Howard ${ }^{8)}$ and Kochel and Piper ${ }^{9)}$, two sprinklers were used in the experiments of Gomez and Mullen ${ }^{10)}$. They investi- 
(a)
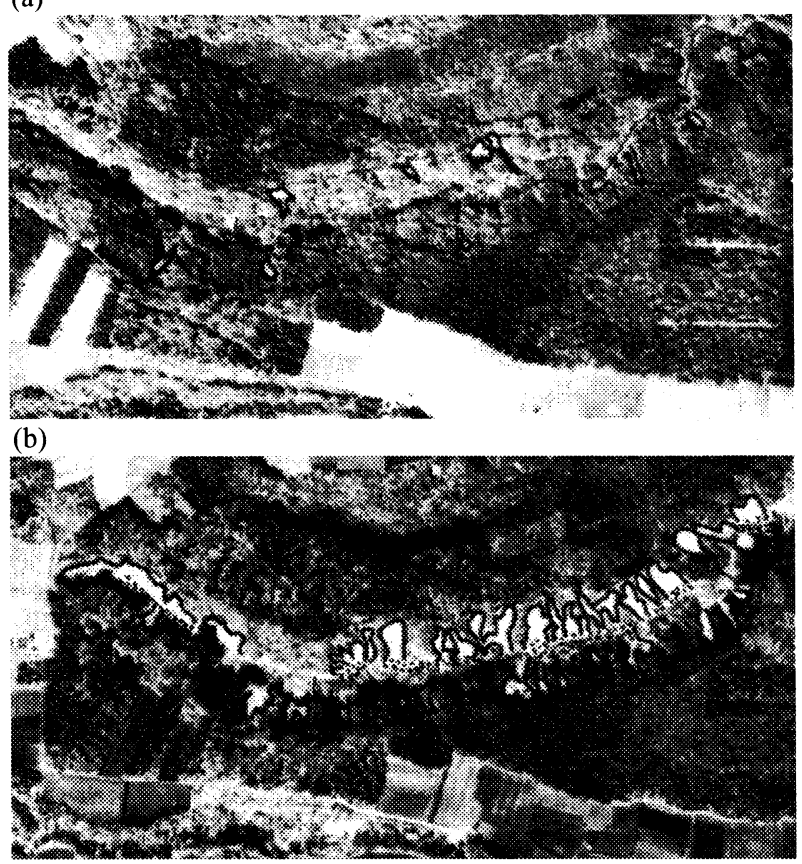

Fig. 1 Aerial photos of the Agatsuma River located in Gumma Prefecture, Japan in (a) 1978 and (b) 1986, where seepage erosion is shown by white areas covered with solid lines.

gated sapped drainage network evolution by calculating the circularity of the network and proposed three phases, initiation, extension and abstraction. The phase of network initiation shows the initial decline in circularity due to the truck stream migration. The phase of extension was characterized when lateral expansion occurred, and the last phase of abstraction was suggested by lateral valley widening and divide decay. They also found that basin sediment discharge declined exponentially with time.

An example of seepage erosion in sediment is shown in Figure 1. Figures $1 \mathrm{a}$ and $\mathrm{b}$ are two aerial photos of the Agatsuma River located in Gumma Prefecture, Japan, taken at the same location in 1978 and 1986, respectively. The land is composed of tephra. The cliff along the river is almost vertical precipice, and seepage is very active there. White areas covered by solid lines show gullies along the cliff. It is found that, in 9 years from 1976 to 1986 , gullies driven by seepage erosion progressed very rapidly.

Seepage erosion was also hypothesized as the dominant factors of channelization in rock. Dunne ${ }^{11)}$ proposed that seepage erosion processes similar to those observed in sediments could occur in rock. However, seepage weathering, such as salt precipitation, chemical dissolution, frost growth, is needed before seepage erosion in rock is possible. As a result, large valleys on the Colorado Plateau, the Hawaiian Islands and Mars were assumed to result from seepage erosion $^{9), 12)}$. However, recently, Lamb et al. ${ }^{13)}$ argued

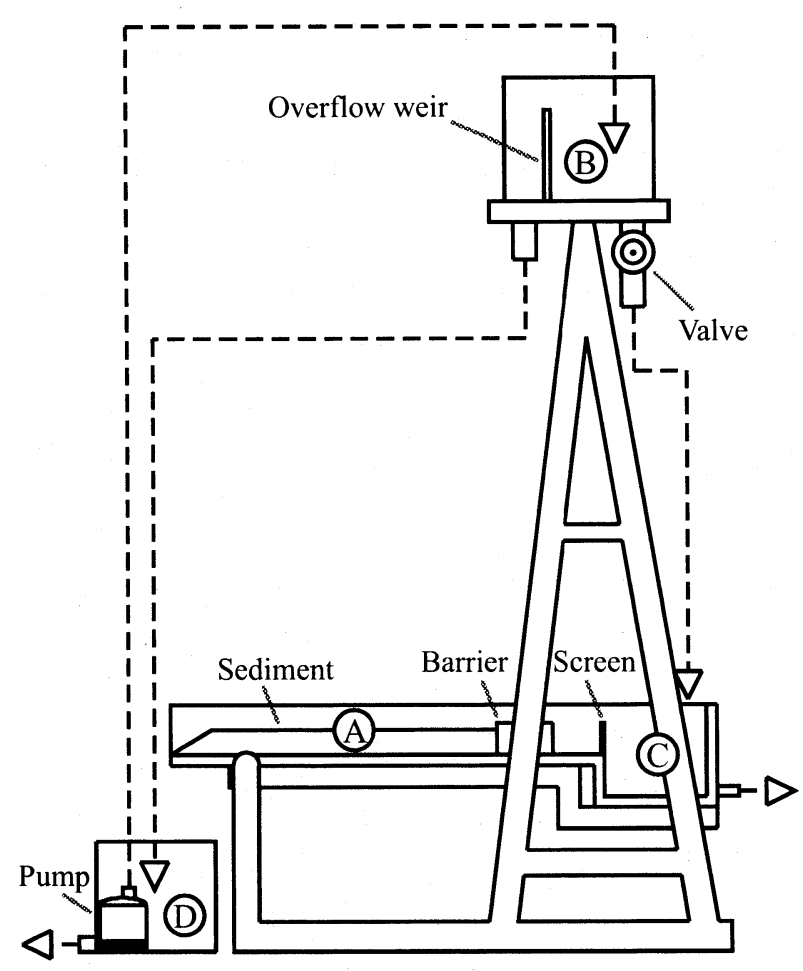

Fig. 2 Side view of the seepage erosion apparatus; dashed lines with arrows show water flow directions, (A) is the experimental chamber, (B) is the top tank, (C) is the upstream reservoir, and $(D)$ is the downstream reservoir.

that the seepage erosion in rock is uncertain. They explained that, in the Colorado Plateau, groundwater seepage cannot remove boulders and gravel that lie on the canyon floor, but high-magnitude flash floods are possible. In Hawaiian basalts, they found no direct evidence of seepage erosion. As a result, they proposed that the amphitheater-headed valleys in the Colorado Plateau and the Hawaiian Islands, formally related to the seepage erosion, are carved by other processes such as waterfall and plunge pool.

It is clear that, at present, we still lack the knowledge of the actual erosion mechanism responsible for seepage erosion. Comparing with previous studies of the three-dimensional experiments, this study aims to investigate the fundamental scales of gullies in terms of layer thickness, chamber slope and water discharge. A series of the three-dimensional systematic experiments was conducted for a wide range of layer thickness and chamber slope. Uniform coarse plastic pellets used as sediment have an advantage of sediment reuse and provided satisfactory results.

\section{Experimental setup}

Figure 2 shows the side view of the seepage apparatus. Water flow directions are indicated by dashed lines with arrows in the figure, and (A), (B), (C) and (D) show portions of the apparatus: the experimental 


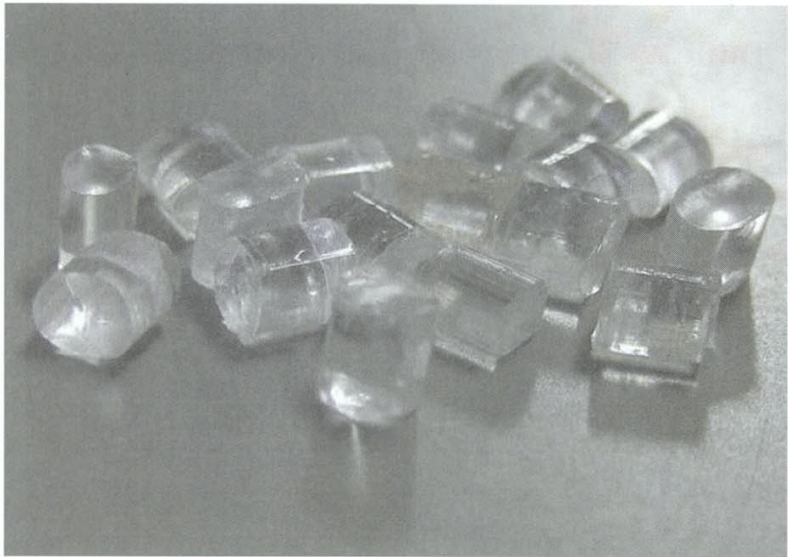

Fig. 3 Cohesionless artificial plastic pellets (Acrylic, PMMA) used as sediment.

chamber, the top tank, the upstream reservoir and the downstream reservoir, respectively. At the top tank, constant water level is fixed by an overflow weir. Water discharge from the top tank flowing down to the upstream reservoir is controlled by a valve. When water level in the upstream reservoir becomes sufficiently high, water will overflow through a narrow-opening screen to the experimental chamber. The screen is used for creating laterally uniform flow. Before the water reaches the upstream face of sediment layer, it has to flow through a wire mesh barrier, used for supporting the sediment layer. The dimensions of sediment layer are $150 \mathrm{~cm}$ in width and $120 \mathrm{~cm}$ in length, but the thickness can be varied. The chamber can be tilted to the desired slope. We glued sand grains on the surface of the chamber bed in order to increase the friction resistance. At the downstream face of the sediment layer, a scarp with the slope of 1:2 (vertical:horizontal) in reference of the chamber bed is created. In every experiment, subsurface water flows through the sediment under the upland surface and emerges at the scarp (seepage face) where channels will be initiated by seepage erosion. Then, water and entrained sediment will fall down to the downstream reservoir, where water is circulated to the top tank by a pump.

Figure 3 shows the material used as sediment in this study. Cohesionless artificial plastic pellets (Acrylic, PMMA) are used in this study. The pellet has the shape of an elliptic cylinder with approximately $3 \mathrm{~mm}$ in major axis, $2 \mathrm{~mm}$ in minor axis and $3 \mathrm{~mm}$ in height. The specific gravity is 1.19 , and the angle of repose is about $54^{\circ}$. Before the start of every experiment, we mix sediment with water in order to maintain the same moisture condition. During the experiment, water discharge is controlled by the valve connected between the top tank and the upstream reservoir. Generally, water discharge will be gradually increased every $5 \mathrm{~min}$ if the active erosion does not take place. Two CCD cameras, installed above and in front of the

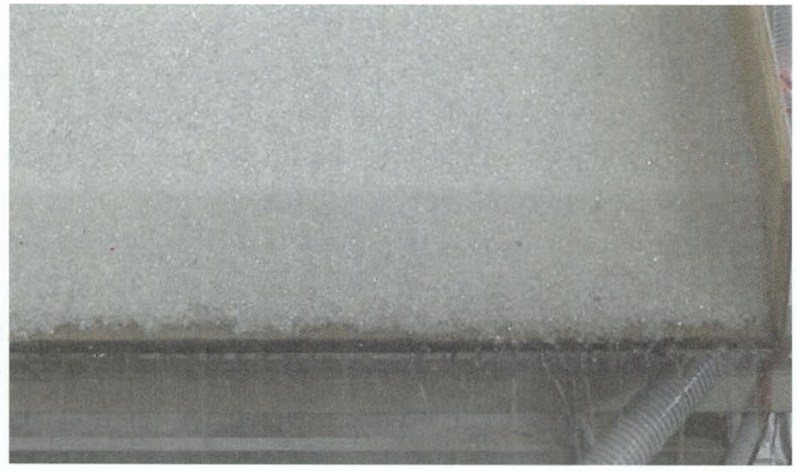

Fig. 4 Groundwater sapping at the toe of the scarp during the beginning of experiments. (photo taken at the left bank)

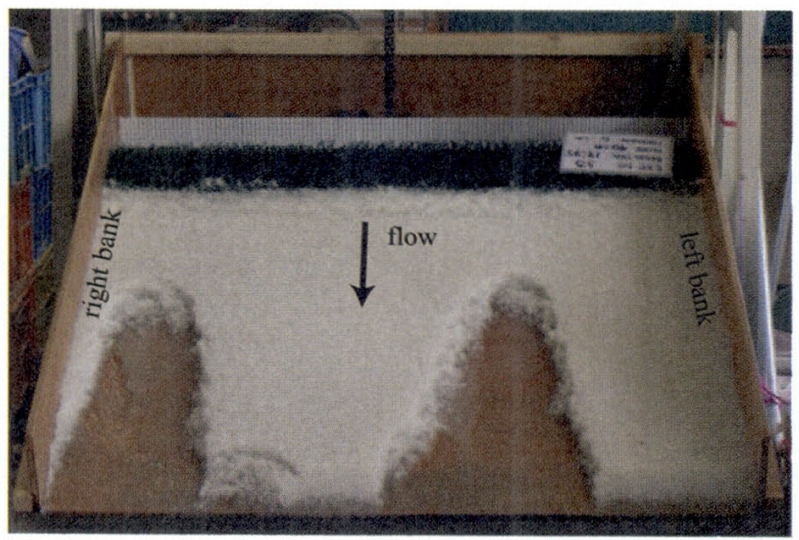

Fig. 5 Evolution of channels with amphitheater heads.

sediment layer, are used to capture the evolution of channels every $15 \mathrm{~s}$ and 30 s, respectively. Discharges are measured every $5 \mathrm{~min}$ by collecting water that falls to the downstream reservoir if no active erosion occurs during the measurement.

\section{Results and discussion}

\subsection{Common characteristics of channeliza- tion}

The common characteristics of the channel evolution by seepage erosion in this study are described in this section. At the beginning of the experiment, we allow small water discharge flowing through the sediment. Thus, small quantity of water emerges from the seepage face randomly and flows down to the downstream reservoir as water droplets. However, some sediment on the scarp, where the seepage occurs, moves out and falls down with water to the downstream reservoir. As we increase water discharge, the seepage expands and covers the whole area of the scarp toe, forming the saturated sapping zone. The water drops become strips of water, and more sediment in the sapping zone is entrained and drops to the downstream reservoir, as shown in Figure 4. As 
water discharge increases further, groundwater sapping induces mass failures on the scarp face. The channels, initiated by mass failures, propagate upstream by the processes of erosion seepage, described as follows. Emerged water discharge along the rim of the channel drives the sediment from the fluvial zone to the downstream reservoir, and, at the same time, the sediment in the sapping zone is entrained to refill the fluvial zone. Thus, sapping groundwater undermines the slope of the channel. As a result, intermittent tension cracks on the upland surface close to the rim occur and, subsequently, cause more mass failures. Amphitheater-headed channels, as observed in the experiments of Kochel and Piper ${ }^{9)}$, can be seen in this study, as shown in Figure 5. During experiment running, erosion process sometimes cease, and that we need to increase water discharge to resume the evolution of channels. It is found that the magnitude of seepage erosion strongly depends on water discharge. However, sediment layer thickness and chamber slope also influence the formation and evolution of channels, and it will be described by four experiments in the following section.

\subsection{Experiments 13, 16, 28 and 32}

Table 1 shows 33 experimental cases with varying sediment layer thickness and chamber slope. Experiments $1-9$, in which thickness is $5 \mathrm{~cm}$, failed because of non-uniform flow in the lateral direction and overland flow by too thin layer thickness. After adjusting the apparatus and increasing the thickness, the experiments were performed successfully except the experiment 17 that the camera battery ran out. The results of the experiments $13,16,28$ and 32 were provided in this section as the typical examples of our experiments. The experiments 13 and 16 have the same initial condition (the thickness and the slope), but the experiment 16 has larger discharge than the experiment 13 . The experiments 13 and 28 have the same chamber slope but differ in sediment layer thickness. The experiments 28 and 32 have the same sediment layer thickness but differ in chamber slope.

Figures 6-7 show the evolution of channels due to seepage erosion in the experimental chamber for four experiments 13, 16, 28, and 32, respectively. Each line shows the evolution of channels with reference to the upland surface at a specific time or a time interval. In the legend of the figures, digits after a line symbol denote a specific time or a time interval in minutes, $*$ denotes that erosion is in unsteady state at that time, "end" denotes the end of experiment, and digits in the blanket denote the maximum, measured discharge in liters per minute at that time. Each experiment will be explained in the following sections.

The result of the experiment 13 is shown in Figure $6 \mathrm{a}$. The sediment layer thickness is $10 \mathrm{~cm}$ with the chamber slope of 0.107 . At $25 \mathrm{~min}$, the discharge was
Table 1 Experimental cases. (In Remark column, "O" means success, and "X" means failure.)

\begin{tabular}{|c|c|c|c|}
\hline Exp. No. & $\begin{array}{l}\text { Thickness } \\
\text { (cm) }\end{array}$ & Slope & Remark \\
\hline 1 & 5 & 0.161 & $\mathrm{X}$ \\
\hline 2 & 5 & 0.161 & $\mathrm{X}$ \\
\hline 3 & 5 & 0.060 & $\mathrm{X}$ \\
\hline 4 & 5 & 0.161 & $\mathrm{X}$ \\
\hline 5 & 5 & 0.161 & $\mathrm{X}$ \\
\hline 6 & 5 & 0.266 & $\mathrm{X}$ \\
\hline 7 & 5 & 0.161 & $\mathrm{X}$ \\
\hline 8 & 5 & 0.214 & $\mathrm{X}$ \\
\hline 9 & 5 & 0.266 & $\mathrm{X}$ \\
\hline 10 & 10 & 0.161 & $\mathrm{O}$ \\
\hline 11 & 10 & 0.214 & $\mathrm{O}$ \\
\hline 12 & 10 & 0.266 & $\mathrm{O}$ \\
\hline 13 & 10 & 0.107 & $\mathrm{O}$ \\
\hline 14 & 10 & 0.317 & $\mathrm{O}$ \\
\hline 15 & 10 & 0.161 & $\mathrm{O}$ \\
\hline 16 & 10 & 0.107 & $\mathrm{O}$ \\
\hline 17 & 10 & 0.214 & $\mathrm{X}$ \\
\hline 18 & 10 & 0.266 & $\mathrm{O}$ \\
\hline 19 & 10 & 0.317 & $\mathrm{O}$ \\
\hline 20 & 10 & 0.367 & $\mathrm{O}$ \\
\hline 21 & 10 & 0.214 & $\mathrm{O}$ \\
\hline 22 & 8 & 0.107 & $\mathrm{O}$ \\
\hline 23 & 8 & 0.161 & $\mathrm{O}$ \\
\hline 24 & 8 & 0.214 & $\mathrm{O}$ \\
\hline 25 & 8 & 0.266 & $\mathrm{O}$ \\
\hline 26 & 8 & 0.317 & $\mathrm{O}$ \\
\hline 27 & 8 & 0.367 & $\mathrm{O}$ \\
\hline 28 & 6 & 0.107 & $\mathrm{O}$ \\
\hline 29 & 6 & 0.161 & $\mathrm{O}$ \\
\hline 30 & 6 & 0.214 & $\mathrm{O}$ \\
\hline 31 & 6 & 0.266 & $\mathrm{O}$ \\
\hline 32 & 6 & 0.317 & $\mathrm{O}$ \\
\hline 33 & 6 & 0.367 & $\mathrm{O}$ \\
\hline
\end{tabular}

16.12liter/min, the saturated sapping zone was clearly observed on the scarp. However, the seepage was not strong enough to cause a mass failure. We increased the discharge at 26min. Between 29-30min, the first mass failure suddenly occurred at $20 \mathrm{~cm}$ from the right bank. However, it stopped within a few minutes later. At $35 \mathrm{~min}$, the discharge measured $16.89 \mathrm{liter} / \mathrm{min}$. As the discharge increased further, the slope close to the center of the scarp collapsed, when elapsed time was $40 \mathrm{~min}$. At this location, the channel progressed very fast. Seepage erosion simultaneously occurred all along the rim of the channel, and that it caused the center channel wider and longer. When the center channel reached the upstream end at $45 \mathrm{~min}$, we 

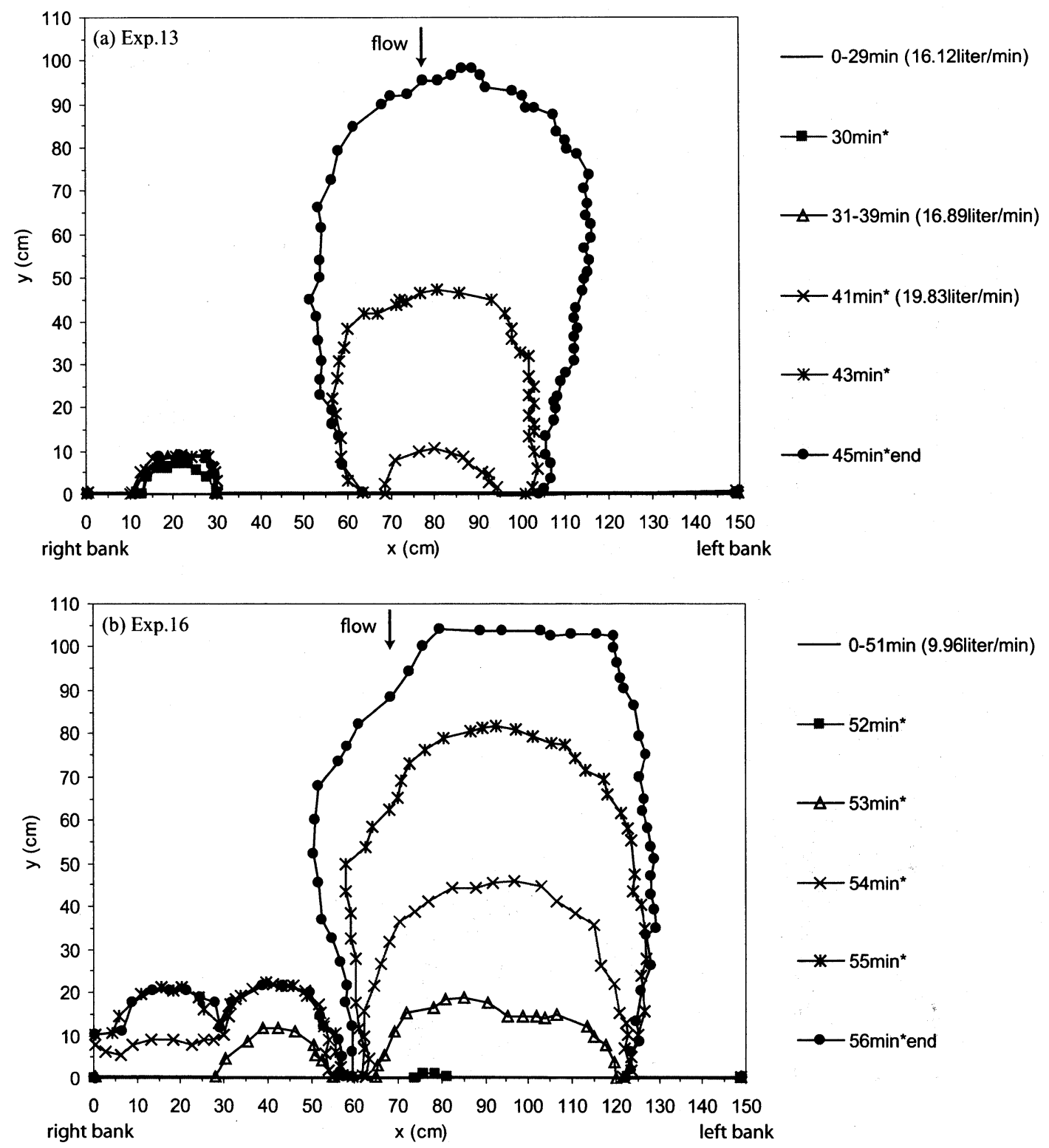

Fig. 6 Evolution of channels. (a) Experiment 13 and (b) Experiment 16, where sediment layer thickness is $10 \mathrm{~cm}$ and chamber slope is 0.107 .

stopped the experiment. The head cut formed an amphitheater head with the spoon-shaped plan view, in which the center width of channel was larger than its downstream end at the scarp. This shape is presumably a light-bulb shape in Kochel and Piper')'s run 7 that they hypothesized that the shape mimics the process of erosion when head cutting reaches a highlevel aquifer. However, the first initiated channel near the right bank did not propagate at all after $31 \mathrm{~min}$.

The experiment 16 has the same initial conditions as the experiment 13 . At $51 \mathrm{~min}$, we increased the discharge well above the erosion threshold. The discharge is larger than that in the experiment 13. Due to the large discharge, the seepage erosion and the evolution of channels were very active, as shown in Figure $6 \mathrm{~b}$. More gullies with larger scale of the width were observed. Howard ${ }^{8)}$ found that high discharge causes more active channels with wider width. The present study confirmed his result. Water discharge is found to be an essential parameter that determine the initiation and evolution of channels.

In the experiment 28 , the sediment layer thickness reduces from $10 \mathrm{~cm}$ to $6 \mathrm{~cm}$, but the chamber slope is still the same as the experiment 13 . Figure 7a shows the channel evolution with time. In this experiment, due to thin thickness, we observed high water depth rising very close to the upland surface. Although, it does not show in this paper, we did try the experiment with $5 \mathrm{~cm}$ thick and found that overland flow occurred at the furthermost upstream and eroded the sediment very rapidly. At $45 \mathrm{~min}$, the discharge measured 22.06 liter $/ \mathrm{min}$. At $46 \mathrm{~min}$ after increasing dis- 

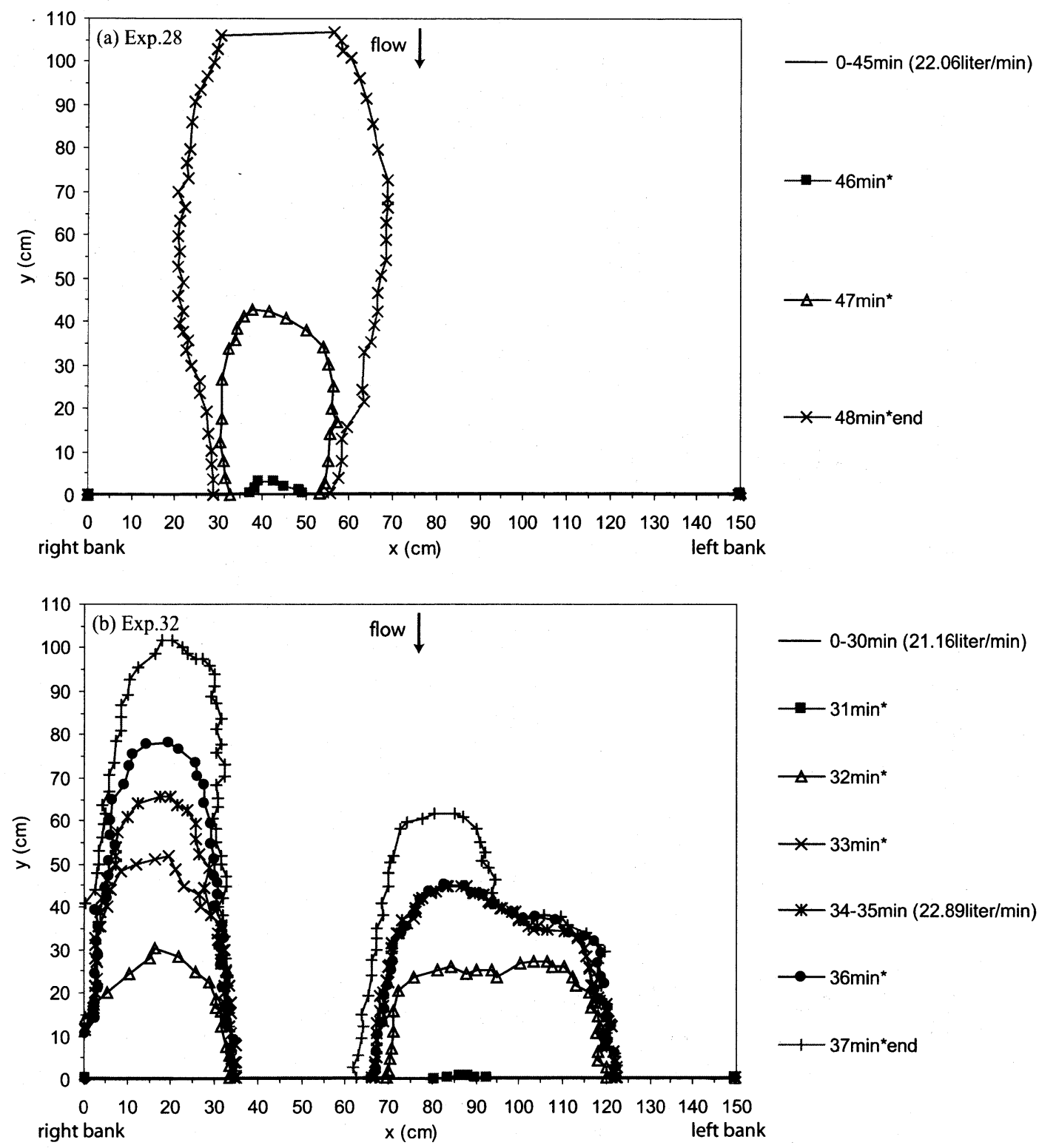

Fig. 7 Evolution of channels. (a) Experiment 28 with chamber slope of 0.107 and (b) Experiment 32 with chamber slope of 0.317 , where sediment layer thickness is $6 \mathrm{~cm}$.

charge further, the slope at approximately $45 \mathrm{~cm}$ from the right bank collapsed, and the sediment eroded rapidly and uniformly until the end of the experiment at $48 \mathrm{~min}$, when the seepage erosion reached the upstream end. We observed high water depth not only inside the sediment but also in the fluvial zone, where high water depth with entrained sediment flowed to the downstream reservoir. A spoon-shaped plan view of the channel was clearly observed as found in the previous experiments.

Figure $7 \mathrm{~b}$ shows the results of the experiment 32 with the thickness of $6 \mathrm{~cm}$ and the chamber slope of 0.317 that is steeper than three previous experiments. At $31 \mathrm{~min}$, two large slope failures took place at the right bank and near the center. The erosion was so large that more than half of the seepage face was col- lapsed. Due to the large width of the center channel, it was not eroded uniformly along its rim, but the erosion swing from one side to the other side. The swing of head cutting corresponds to the movement of sediment in the fluvial zone. It implies that bifurcation is more pronounced when the chamber slope becomes steeper. Then, the seepage erosion of the channel near the center ceased at $33 \mathrm{~min}$, whereas the erosion of the channel at the right bank continued until the time elapse of $34 \mathrm{~min}$. The discharge measured $22.89 \mathrm{liter} / \mathrm{min}$ at $35 \mathrm{~min}$. As we increased water discharge further, erosion resumed, and we stopped the experiment at $37 \mathrm{~min}$. Although the head cuts formed amphitheater heads similar to two previous experiments, their plan view did not form spoon shapes. 

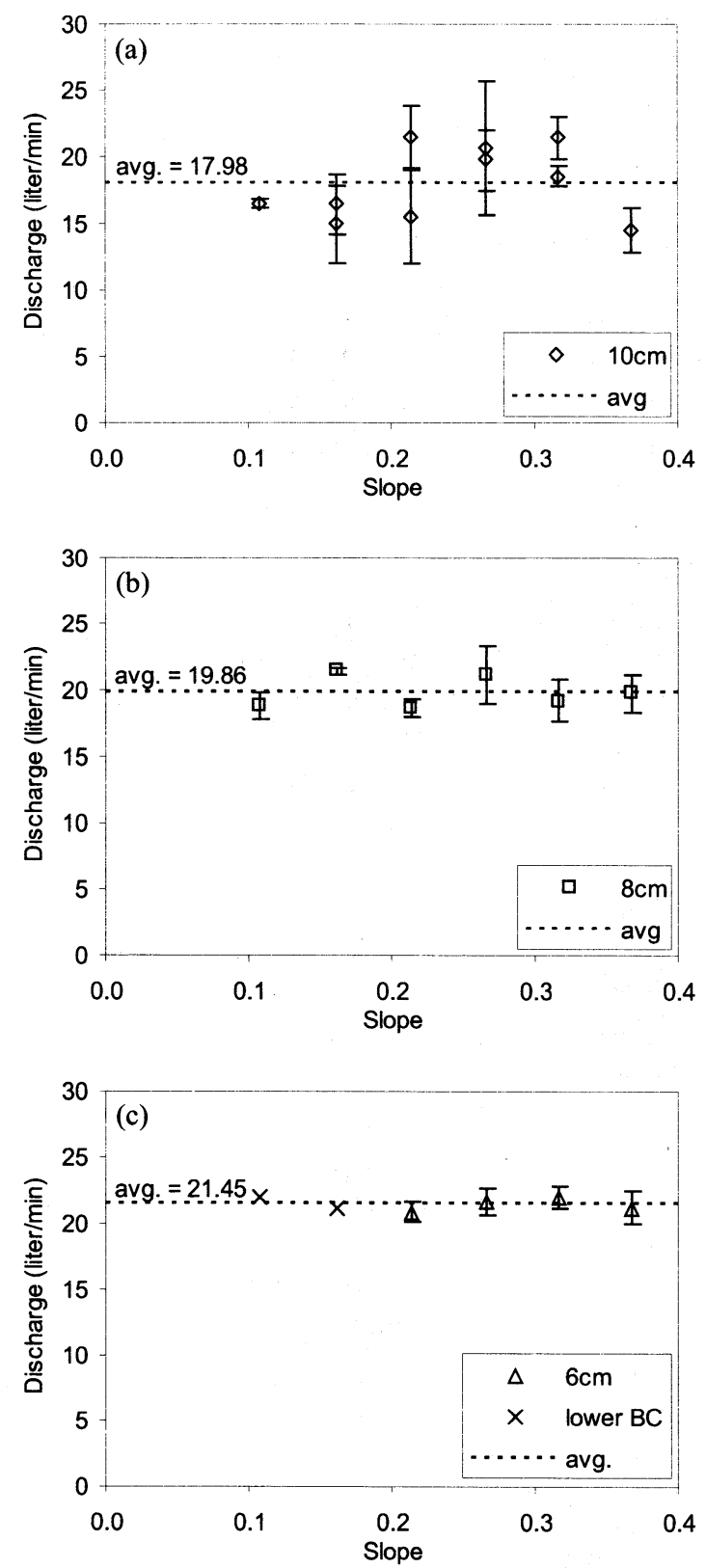

Fig. 8 Threshold water discharge for channel initiation with chamber slope and sediment layer thickness: (a) $10 \mathrm{~cm}$ thick, (b) $8 \mathrm{~cm}$ thick and (c) $6 \mathrm{~cm}$ thick. (The range of each point shows that the threshold water discharge in the experiment is expected in that interval, and "lower BC" means that only the lower boundary of the threshold water discharge was collected.)

\subsection{Channel initiation}

Figures 8a-c show the threshold water discharges that initiate channels in the experiments with chamber slope from 0.107 to 0.367 and sediment layer thickness of 10,8 and $6 \mathrm{~cm}$, respectively. However, as we cannot measure the exact threshold water discharges, they was estimated by the discharges before and af-

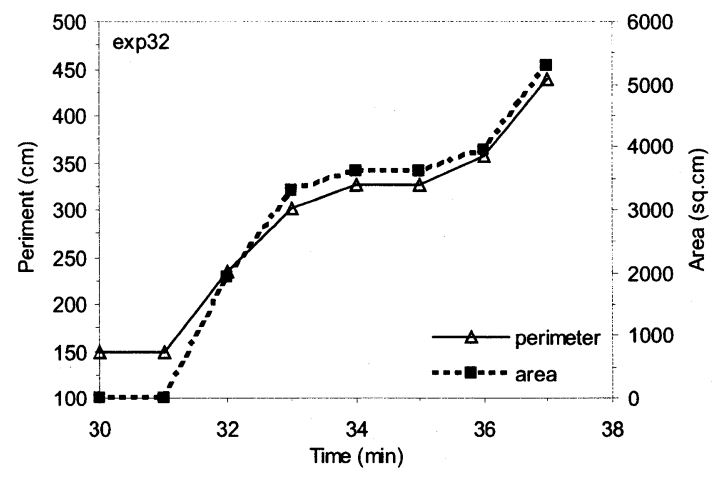

Fig. 9 Evolution in channel perimeter (solid line) and erosion area (dashed line) with time in Experiment 32.

ter channel initiation. Thus, the upper and lower ranges of each point mean the measured discharges before and after channel initiation, respectively. In Figure $8 \mathrm{a}$, for sediment thickness of $10 \mathrm{~cm}$, some experiments show a wide range of expected threshold erosion because of the unintentional increase of discharge. Nevertheless, those experiments represented the results corresponding to the discharge well above the threshold erosion. The experiments with sediment layer thickness of 8 and $6 \mathrm{~cm}$ in Figures $8 \mathrm{~b}$ and $c$ show narrow ranges of the values. From the figures, we found no clear relationship between chamber slope and the threshold water discharge. The results are contrast to the impression that the additional downstream gravitational force by increasing bed slope should reduce the stability of the sediment. However, the average values of the threshold water discharge of 10,8 and $6 \mathrm{~cm}$ differ and have the values of $17.98,19.86$ and $21.45 \mathrm{liter} / \mathrm{min}$, respectively. As a result, the threshold water discharge increases with decreasing sediment layer thickness. A decrease in thickness possibly increases the stability of slope failure since sediment weight is one of the driving forces. Thus, larger discharge is needed to initiate the slope failure in shallower sediment layer.

\subsection{Channel evolution}

Figure 9 shows the evolution of channels with time in the experiment 32. Channel perimeter and erosion area are chosen as indicators. It is found that both perimeter and area increase as time progresses. However, Gomez and Muller ${ }^{10}$ ) found that, at the last stage of network evolution in their cxpcrimcnt, crosion area increases, while perimeter decreases. At that stage of mature evolution, which they called the phase of abstraction, lateral valleys widen, and divides decay due to merging. This mature stage was not observed in our experiments due to a possible reason that our sediment is much coarser than fine sand with median size of $0.23 \mathrm{~mm}$ used in their experiment. Thus, our 


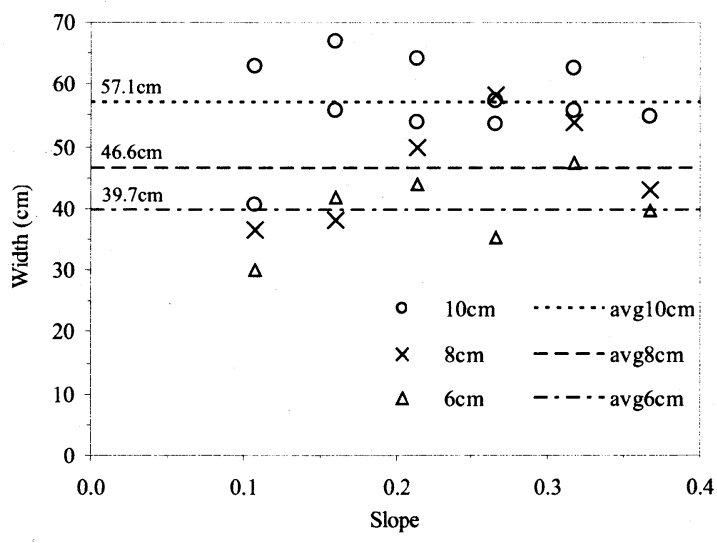

Fig. 10 Dominant channel width with chamber slope and sediment layer thickness

apparatus is not large enough to perform the mature stage.

Figure 10 shows the relationship between the width of the dominant channel, chamber slope and sediment layer thickness. The dominant channel is chosen from the largest channel found in each experiment. From the experimental results, we found that the width of channels changed very little after channel initiation, but the length of channels actively propagated by head cutting. From the figure, no clear relationship between channel width and chamber slope is found. However, the averaged values of channel width for different sediment layer thickness show that the width decreases as the thickness decreases. It is possible that the scale of channel width corresponds to the scale of mass failure, and that an increase of layer thickness induces larger scale of mass failure.

\section{Conclusion}

A series of the experiments of seepage erosion with cohesionless sediment was conducted with varying water discharge, sediment layer thickness and chamber slope. The processes of seepage erosion were observed in the experiments such as groundwater sapping, sediment transport in the fluvial zone, tension cracks, and slope failures. Amphitheater head of channels due to seepage erosion were also observed in the experiments. From the experiments, water discharge was found to be a dominant parameter in controlling the formation and evolution of channels. The magnitude of erosion strongly depends on water discharge. In addition, with the same sediment layer thickness and chamber slope, higher discharge initiates more gullies with larger scale of width. As sediment layer thickness decreases, we found that the width of channels becomes smaller, but the threshold water discharges to initiate channels increase. If chamber slope is mild, high water depth can be seen, and seepage erosion si- multaneously occurs along the rim resulting in the spoon-shaped channel. As chamber slope becomes steeper, seepage erosion swings from one side of channel to the other side, and the shape is less symmetric.

\section{Acknowledgement}

This study was support by the Japan Society for the Promotion of Science (JSPS) Postdoctoral Fellowship Program. We acknowledge Upaka Sanjeewa Rathnayake, Master Student, Hokkaido University, who assisted in doing the experiments.

\section{REFERENCES}

1) Izumi, N. and G. Parker: Inception of channellization and drainage basin formation: upstreamdriven theory, J. Fluid Mech., Vol. 283, pp. 341363, 1995.

2) Izumi, N. and G. Parker: Linear stability analysis of channel inception: downstream-driven theory, J. Fluid Mech., Vol. 419, pp. 239-262, 2000.

3) Izumi, N. and K. Fujii: Channelization on plateaus composed of weakly cohesive fine sediment, J. Geophys. Res., Vol. 111, F01012, doi:10.1029/2005JF000345, 2006.

4) Pornprommin, A., N. Izumi and T. Tsujimoto: Linear stability analysis of channel inception on slopes with arbitrary shapes: purely erosional case, J. Applied Mechanics, Vol. 7, JSCE, pp. 997-1004, 2004.

5) Pornprommin, A., N. Izumi and T. Tsujimoto: Inception of Channelization on Slopes with Arbitrary Shapes: Erosional and Depositional Case, 4th IAHR Symposium on River, Coastal and Estuarine Morphodynamics, Illinois, IAHR, pp. 1127-1136, 2005.

6) Dunne, T.: Hydrology, mechanics, and geomorphic implications of erosion by subsurface flow, in Groundwater Geomorphology: The Role of Subsurface Water in Earth-Surface Processes and Landforms, edited by C. G. Higgins and D. R. Coates, Spec. Pap. Geol. Soc. Am., 252, pp. 128, 1990.

7) Howard, A. D. and C. F. McLane: Erosion of cohesionless sediment by groundwater seepage, Water Resour. Res., Vol. 24(10), pp. 1659-1674, 1988.

8) Howard, A. D.: Groundwater Sapping Experiments and Modeling, in Sapping Features of the Colorado Plateau: A Comparative Planetary Geology Field Guide, edited by A. D. Howard, R. C. Kochel, and H. Holt, NASA Spec. Publ., SP-491, pp. 71-83, 1988.

9) Kochel, R. C. and J. F. Piper: Morphology of large valleys on Hawaii: Evidence for groundwater sapping and comparisons with Martian valleys, J. Geophys. Res., Proc. Lunar Planet Sci. 
Conf. 17th Part 1, Vol. 91, suppl., pp. E175-E192, 1986.

10) Gomez, B. and V. T. Mullen, An experimental study of sapped drainage network development, Earth Surf. Processes Landforms, Vol. 17, pp. 465-476, 1992.

11) Dunne, T.: Formation and controls of channel networks, Prog. Phys. Geogr., Vol. 4, pp. 211-239, 1980.
12) Laity, J. E. and M. C. Malin: Sapping processes and the development of theater-headed valley networks on the Colorado Plateau, Geol. Soc. Amer. Bull., Vol. 96, pp. 203-217, 1985.

13) Lamb, M. P., A. D. Howard, J. Johnson, K. X. Whipple, W. E. Dietrich and J. T. Perron: Can springs cut canyon into rock?, J. Geophys. Res., Vol. 111, E07002, doi:10.1029/2005JE002663, 2006.

(Received April 14, 2008) 